\title{
MASTRO ESTENDÍVEL MANUALMENTE PARA A OBTENÇÃO DE FOTOGRAFIAS “AÉREAS” INCLINADAS
}

\author{
Attilio Antonio Disperati ${ }^{1}$, Fábio Henrique de Almeida ${ }^{2}$, Sérgio Xavier de Mendonça Júnior ${ }^{3}$, \\ Caciane Peinhopf ${ }^{4}$, Bárbara Dalgallo ${ }^{5}$ \\ ${ }^{1}$ Eng. Florestal, Ph.D., Depto. Eng. Florestal, UNICENTRO, Irati, PR, Brasil \\ ${ }^{2}$ Eng. Florestal, Fibria, Três Lagoas, SP, Brasil - faheal@ hotmail.com \\ ${ }^{3}$ Fotógrafo - www.fotomen.com.br \\ ${ }^{4}$ Eng ${ }^{a}$ Florestal, UNICENTRO, Irati, PR, Brasil - cacianepeinhopf@ hotmail.com \\ ${ }^{5}$ Eng $^{\mathrm{a}}$ Florestal, UNICENTRO, Irati, PR, Brasil - babidalgallo@ hotmail.com \\ Recebido para publicação: 13/06/2008 - Aceito para publicação: 21/03/2011
}

\begin{abstract}
Resumo
O presente artigo relata o desenvolvimento e a utilização de mastro estendível manualmente para a captura de fotografias aéreas. Inicialmente, testou-se a fixação de microcâmara de segurança no topo do mastro e, posteriormente, de câmara digital. Incentivado pelos resultados iniciais, obteve-se uma plataforma e um sistema fotográfico que possibilitava acionar, girar e inclinar uma câmara fotográfica digital por controle remoto instalada no topo do mastro, viabilizando a tomada de fotografia aérea inclinada, panorâmica e sequencial, com giro de até 360 graus. O conjunto é constituído por: (1) mastro estendível até oito metros; (2) tripé; (3) plataforma e sistema fotográfico; (4) maleta com o sistema de captura e observação da imagem em tempo real; e (5) caixa de ferramentas. Foram obtidas 1887 fotografias digitais e 21 vídeos em dezoito ocasiões, utilizados nas seguintes finalidades: individual, multitemporal e elaboração de mosaicos fotográficos. A plataforma e o sistema podem ser aperfeiçoados visando maior facilidade de uso. Estudos específicos direcionados à árvore individual realçariam o potencial da técnica. O mastro estendível é uma ferramenta a mais de trabalho, de baixo custo, adicionada à caixa de ferramentas do sensoriamento remoto, com aplicações limitadas somente pela imaginação dos usuários.

Palavras-chave: Fotointerpretação florestal; aquisição de fotos; câmara digital; fotografias em baixa altitude; árvore individual.
\end{abstract}

\begin{abstract}
Extensible manually mast for acquisition of oblique "aerial" photographs. This paper presents the experience of using a manual telescopic mast in order to take aerial photographs. First of all, a security micro-camera was fixed to the top of a mast and, later on, a digital camera. Due to the first results, a frame and a photographic system had been developed, allowing to shoot, to rotate and to incline the digital camera by remote control, which fixed to the top of the mast would allow taking oblique, panoramic and sequential aerial photos with 360 degrees range. The final system consists of (1) an extensible telescopic mast up to eight meters, (2) tripod, (3) the frame and photographic system, (4) a small box containing the capturing and observation of real time images system and a (5) tool box. During the research it was taken 1887 digital photographs and 21 videos for the following purposes: individual, multi-temporal and photo mosaics mounting. The final frame and photographic system can be improved in order to make easy the photos taking. Specific forest studies toward an individual tree would enhance the potential of the technique. The telescopic mast is an additional tool for Remote Sensing toolbox and that, due the lower cost, is limited only by the user's imagination.

Keywords: Forest photointerpretaion; photo acquisition; digital camera; low altitude photographs; individual tree.
\end{abstract}

\section{INTRODUÇÃO}

$\mathrm{Na}$ atividade de mapeamento e de monitoramento dos recursos naturais de uma região, há a necessidade de obtenção de fotografias aéreas e/ou terrestres como material primário ou mesmo de apoio 
para a análise das imagens analógicas ou digitais disponíveis.

A obtenção das fotografias aéreas apresenta um custo alto, sendo executada por empresa de aerolevantamento, que utiliza uma plataforma móvel (avião ou qualquer outra aeronave), atingindo três mil metros de altura de voo ou mais, e uma sofisticada câmara aerofotogramétrica (resultando fotografias de tamanho $23 \times 23 \mathrm{~cm}$ ). Em contrapartida, a obtenção de fotografias terrestres é feita manualmente, utilizando-se uma câmara fotográfica digital e a uma altura máxima do solo de aproximadamente dois metros, por meio da elevação dos braços.

$\mathrm{Na}$ obtenção das fotografias terrestres, algumas vezes é necessário aumentar essa altura de captura, a fim de ultrapassar obstáculos, resultando em maior área fotografada e proporcionando melhor visão em perspectiva. Nesse sentido, Colwell (1963), brilhantemente, apresentou exemplos práticos de fotografias obtidas de posições estratégicas do terreno, do alto de torres, de árvores, edifícios e também de outras plataformas fixas ou deslocáveis (idênticas às usadas para efetuar a manutenção de sinal de tráfego e/ou em postes de iluminação elétrica). Fotografias de posições, como as mencionadas, em muito completam as informações extraídas das fotografias aéreas obtidas por meio de plataformas móveis. Disperati et al. $(1993,2007)$ utilizaram fotografias multitemporais (seis épocas no período de um ano) obtidas do topo de edifícios, para o estudo de duas áreas urbanas com vegetação.

Um procedimento efetivo e de mais baixo custo para elevar uma câmara fotográfica a alguns metros do solo é por meio de uma haste ou então de um mastro. A sua fixação vertical no solo pode ser por meio de tripé (idêntico ao usado em topografia) e adicionalmente instalado em veículo ou em carreta. No caso do mastro estendível (denominado também telescópico), suas diferentes partes podem ser estendidas manual ou pneumaticamente.

Existem inúmeros tipos e modelos de mastros, elaborados especialmente para atender situações civis e militares. A ideia de utilizar mastro para a captura de fotografias é antiga, e existem empresas que comercializam mastros e respectivos suportes ou plataformas fotográficas, em geral com custo superior a três mil dólares. O mastro poderá atingir altura de até vinte metros ou mais e suportar diversos equipamentos, como plataformas fotográficas ou de vídeo, instrumentos meteorológicos, de comunicação, verificação da poluição atmosférica e estação de monitoramento de som (CLARK MASTS, 2008, FLOATOGRAPH, 2008 e 2008a; WENZLAU ENGINEERING, 2009).

Em agosto de 2007, iniciou-se a pesquisa para a obtenção de fotografias do tipo "aéreas", utilizando-se mastro estendível manualmente com as seguintes diretrizes:

a) O procedimento seria do geral para o particular, isto é, no início das atividades seriam utilizados materiais (câmaras fotográficas e mastro estendível apoiados em tripé topográfico) disponíveis ou que fossem de baixo custo. A tendência posterior, em função da experiência e dos resultados obtidos, seria a utilização de equipamentos e procedimentos mais sofisticados.

b) A preocupação inicial seria desenvolver e testar uma plataforma para apenas uma câmara fotográfica digital.

c) O material fotográfico seria analisado por meio de softwares de edição de imagens, visando efetuar o realce e a montagem de mosaicos fotográficos não controlados.

O objetivo geral do presente trabalho é relatar a experiência realizada e os resultados obtidos, no período de agosto de 2007 a novembro de 2009, no desenvolvimento da plataforma e do sistema fotográfico para uma câmara digital, visando à captura de fotografias do tipo "aéreas", utilizando um mastro estendível manualmente.

Os objetivos específicos do presente trabalho foram:

a) Desenvolver e testar uma plataforma fotográfica, controlada remotamente, para ser instalada no topo de um mastro estendível manualmente, visando à captura remota de fotografias "aéreas" do tipo quase verticais, inclinadas e panorâmicas.

b) Analisar os diferentes modos de obter fotografias via mastro estendível.

\section{Experiências de captura das fotografias} utilizados:

A pesquisa apresentou duas etapas relacionadas aos diferentes equipamentos e procedimentos

$1^{\mathrm{a}}$ etapa: obtenção inicial das fotografias aéreas (agosto a novembro de 2007);

$2^{\mathrm{a}}$ etapa: utilização de uma plataforma e sistema fotográfico com controle remoto (dezembro de 2007 a outubro de 2009). 
Primeira etapa

Utilizou-se uma microcâmara digital no topo de um mastro estendível até a altura de 3,60 metros. Posteriormente, uma câmara digital foi fixada no topo de mastros estendíveis até 3,60 e até 8,0 m de altura. A seguir são detalhados a metodologia e os resultados dessa etapa.

\section{Microcâmara de segurança}

Utilizou-se uma microcâmara de segurança fixada no topo do mastro estendível até $3,60 \mathrm{~m}$ de altura, o qual era mantido na vertical por meio de um tripé universal em alumínio. O tripé é o mesmo utilizado em trabalhos topográficos com teodolito e estação total. $\mathrm{O}$ mastro, adquirido na empresa curitibana AVR Instrumental Técnico e Científico Ltda., é utilizado para elevar a antena DGPS a fim captar melhor os sinais GPS emitidos pelos satélites.

A microcâmara utilizada foi a SAFECAM (microcâmara de segurança - colorida com áudio e sem fios). Ela possui saída A/V (áudio e vídeo) e com outro adaptador conectava-se a um notebook via porta USB. Para a visualização e a manipulação dos vídeos gravados, foi necessário instalar no notebook o software SUPER DVRX 4.3.2.1, o qual possibilitava visualizar até quatro recepções de microcâmaras.

As imagens obtidas pela microcâmara eram transmitidas em tempo real para um notebook, no qual eram armazenadas automaticamente num diretório predeterminado na instalação do software. Os vídeos possuíam uma resolução de 640 x 480 pixels, com tempo de gravação máxima de 6 minutos e 31 segundos e com taxa de quadros de 29/s. A fixação da microcâmara ao mastro de $3,6 \mathrm{~m}$ foi feita com fita adesiva. Percebeu-se que não havia necessidade de algo mais sofisticado para fixá-la, pois a microcâmara era leve e pequena. No interesse de fotos sequenciais, o mastro era girado manualmente.

Em dias que apresentaram ventos acentuados, ao se erguer todo o mastro, observaram-se imagens distorcidas, constatando-se assim a interferência no sinal de recepção.

Com os vídeos produzidos, foram feitas imagens com extensão.jpg a partir de congelamento de frame da imagem a $1,60 \mathrm{~m}, 2,50 \mathrm{~m}, 3,20 \mathrm{~m}$ e $3,60 \mathrm{~m}$. Constatou-se facilidade na montagem da microcâmara no mastro, porém as imagens adquiridas eram de baixa resolução, impossibilitando análises mais detalhadas das cenas.

\section{Câmara digital no topo do mastro estendível até 3,60 m}

A segunda tentativa foi fixar a câmara digital SONY Cyber-Shot DSC-P73 no topo do mastro estendível até $3,60 \mathrm{~m}$. Ela foi fixada na ponta do mastro também com fita adesiva. Após ativar-se a função time (10 s), a câmara era elevada.

Nessa etapa foram feitas filmagens e fotos. Girando-se o mastro manualmente no tripé, obtiveram-se cenas mais abrangentes, nítidas e com qualidade controlável (até 2304 x 1728 pixels). Foram feitas duas aplicações desse procedimento: avaliação visual de galhas ao longo dos galhos das castanheiras, provocadas por bactérias, e avaliação visual de fotografias de um taquaral.

Encontraram-se algumas dificuldades: nos dias com vento, as imagens perdiam qualidade; a câmara era fixada com fita adesiva; dispêndio de força física para levantar o mastro para a filmagem ou captura das fotografias.

\section{Mastro estendivel até $8,0 \mathrm{~m}$}

As experiências anteriores já confirmavam a necessidade de utilizar mastros que atingissem maiores alturas. Decidiu-se utilizar o mastro estendível até $8,0 \mathrm{~m}$, da empresa já citada, AVR Instrumental.

Face ao tamanho do mastro, por questão de segurança e visando melhor estabilidade em campo, foi adquirido também um tripé especial universal em alumínio, sendo cada perna estendível até $1,8 \mathrm{~m}$. Primariamente, tal mastro e tripé foram utilizados para levantar a antena do DGPS visando à melhor captação dos sinais emitidos pelos respectivos satélites.

As fotografias foram obtidas em duas ocasiões, sendo em um taquaral (Figura 1) e em um reflorestamento de Pinus spp., de quatro anos de idade, com altura média de 6,0 m e espaçamento de $1,0 \times 1,0 \mathrm{~m}$.

As dificuldades anteriores se repetiram, e agora com mais intensidade o dispêndio de força física, pois a quantidade de fotografias aumentou e o peso do mastro também para ser erguido. Não havia possibilidade de acionar remotamente a câmara fotográfica, visto continuamente estar captando a imagem no modo programado de captura automática, num determinado intervalo de tempo. 

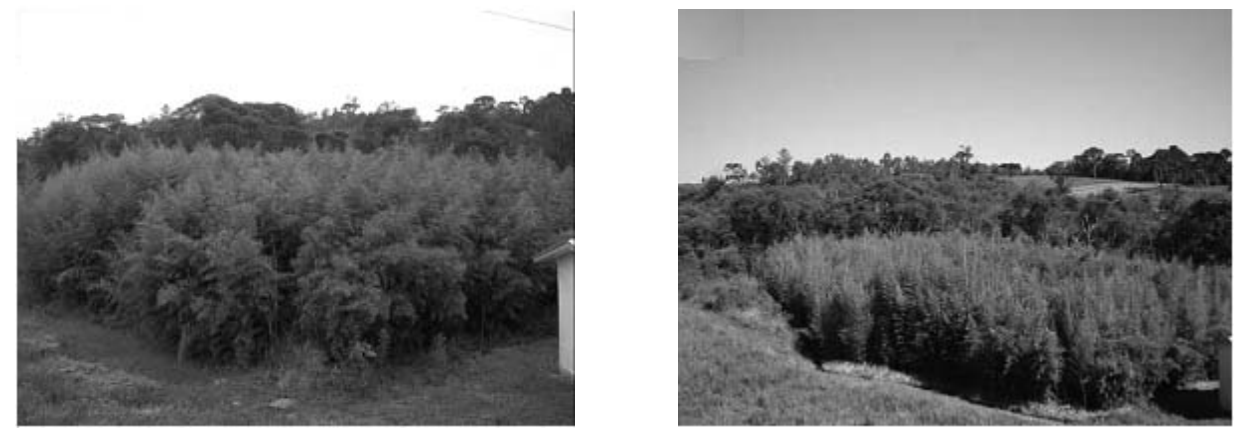

Figura 1. Imagens obtidas do taquaral a 3,60 $\mathrm{m}$ (esquerda) e a 8,00 $\mathrm{m}$ de altura (direita).

Figure 1. Images acquired of the bamboo plantation taken at $3.60 \mathrm{~m}$ (left) and $8.0 \mathrm{~m}$ high (right).

Segunda etapa: utilização de radiocontrole

Os fatos evidenciados reforçaram a necessidade imperativa de um sistema eletrônico que acionasse a câmara fotográfica a distância, ou melhor, por meio de comandos de controle remoto, a fim de facilitar a captura das imagens individuais ou mesmo sequenciais e evitar a necessidade de girar manualmente o mastro.

Com base na técnica do aeromodelismo de controle a distância, desenvolveu-se um sistema fotográfico, para uma câmara digital, que propiciasse o disparo na câmara, assim como efetuar a sua rotação horizontal e vertical, por meio de radiocontrole.

A câmara digital (Canon PowerShot SD700 IS) e os demais acessórios foram instalados em uma estrutura de alumínio (plataforma) apoiada diretamente no topo do mastro, favorecendo assim a captura de fotografias quase que verticais, inclinadas e com possibilidade de giro de 360 graus. O tripé reforçado propiciou maior segurança e melhor estabilidade do conjunto plataforma/sistema fotográfico no topo do mastro.

Nos dias com fortes ventos, verificou-se a instabilidade do mastro, porém as fotos obtidas por esse sistema eram nítidas e não trêmulas (Figura 2), devido ao sistema de estabilização de imagem-função da câmara utilizada. Por questão de segurança, instalou-se um contrapeso (saco de pedras pequenas) na outra extremidade da barra que suportava o sistema fotográfico e de peso idêntico ao do sistema fotográfico (cerca de 780 gramas).
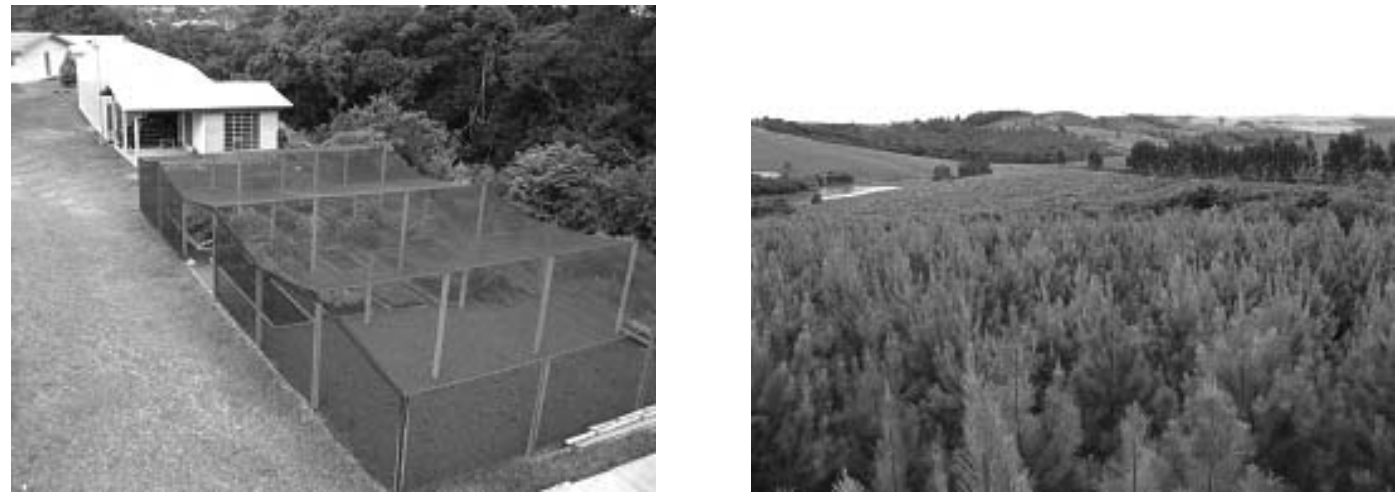

Figura 2. Imagens obtidas a $8 \mathrm{~m}$ de altura, de parte de um viveiro florestal (esquerda) e de um talhão de Pinus spp. (direita). Fonte: Disperati, 2009.

Figure 2. Images acquired at $8 \mathrm{~m}$ high, part of a forest nursery (left) and a stand of Pinus spp. (right). Source: Disperati, 2009.

Efetuaram-se filmagens e captura de fotografias individuais com o movimento lento e quase que horizontal da câmara em giro de $360^{\circ}$. As montagens das fotografias individuais e sequenciais, visando à geração dos mosaicos não controlados, foram feitas no Adobe Photoshop.

Com o novo sistema, facilitaram-se as tomadas de fotografias. Ao se levantar uma vez o mastro de 
8,0 m, era possível capturar todas as fotografias necessárias. Entretanto, foi necessário mais um equipamento (uma caixa contendo o sistema radiocontrolado e o radiocontrole propriamente dito), a ser transportado até o local de tomadas das fotografias, acarretando a necessidade de mais pessoas para utilizar o sistema.

Após alguma experiência de uso do conjunto mastro estendível até $8 \mathrm{~m}$, plataforma e sistema fotográfico, e no intuito de facilitar ainda mais a captura das fotografias, no sistema fotográfico foi instalado um sistema de transmissão, a fim de mostrar em tempo real, num pequeno monitor de aparelho DVD, a imagem observada pela lente da câmara digital. Entretanto, testes posteriores indicaram que a instalação de tal facilidade, além de aumentar um pouco o peso do sistema fotográfico, eliminou a opção de capturar fotos quase que verticais, mas permanecendo ainda a tomada de fotos inclinadas e panorâmicas (câmara na horizontal).

Apesar da limitação acima mencionada, ficou evidente que a observação, em tempo real, da imagem a ser capturada facilitava enormemente a tarefa da tomada das fotografias, as quais continuaram a ser tomadas isoladas ou continuamente, visando à montagem de mosaicos fotográficos.

Uma das dificuldades na utilização prática do conjunto plataforma/sistema fotográfico era a atenção necessária e cuidadosa aos diversos tipos de baterias usadas no conjunto. Utilizavam-se quatro tipos diferentes de baterias:

a) uma bateria interna de $12 \mathrm{~V}$, para observar a imagem captada na tela do aparelho de DVD;

b) uma bateria interna de $9 \mathrm{~V}$ no radiocontrole, para acionar os diversos comandos de movimentos na plataforma e no sistema fotográfico;

c) uma bateria Litium polímero para o sistema de transmissão de vídeo instalado na plataforma do sistema fotográfico;

d) quatro baterias (pilhas do tipo AA), instaladas na plataforma, que acionavam os comandos de rotação e de inclinação do sistema fotográfico.

Para cada tipo de bateria, necessitava-se de um carregador diferente. Um dia antes de cada missão fotográfica, era necessário testar todas as quatro baterias e, se necessário, carregá-las.
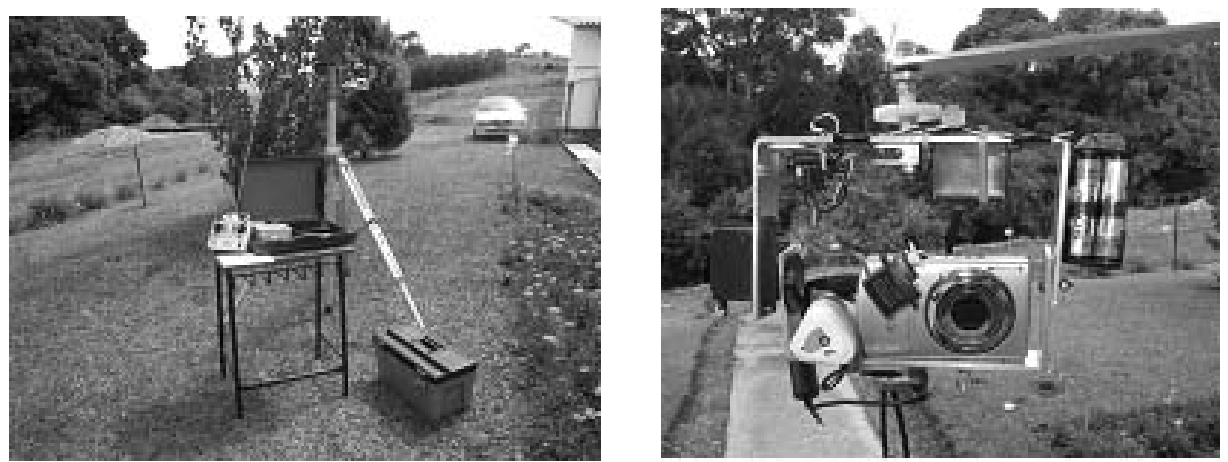

Figura 3. Parte do sistema de mastro estendível (esquerda) e a plataforma e o sistema fotográfico (direita). Fonte: Disperati, 2009.

Figure 3. Part of extendible mast assembly (left) and the platform and photographic system (right).

Em maio de 2009, a engrenagem de plástico que girava o sistema fotográfico na plataforma quebrou. Em face disso, decidiu-se aperfeiçoar o conjunto plataforma/sistema fotográfico. Substituiu-se a bateria do sistema de transmissão por uma do tipo Litium que, dessa vez, alimentava a tela de LCD e o receptor de vídeo de $2,4 \mathrm{GHz}$, e utilizou-se uma engrenagem maior para girar o sistema fotográfico por controle remoto. Apesar de tal bateria ser menos potente e mais pesada do que a correspondente Litium polímero, ela é mais estável quanto à carga e menos sujeita à perda devido ao "estufamento". Além dessas modificações técnicas, para facilitar o transporte, em campo, de todo o material, instalou-se em uma maleta todo o sistema de captura e observação da imagem em tempo real. Além disso, para facilidade de transporte, a plataforma/sistema fotográfico, o equipamento de radiocontrole e demais ferramentas e baterias de reserva foram devidamente instaladas em uma caixa plástica.

A figura 3A mostra todo o conjunto (tripé e mastro estendível, equipamento de radiocontrole, maleta com o sistema de observação da imagem e a caixa de ferramentas), enquanto que a figura 3B 
evidencia a plataforma e o sistema fotográfico em uso (novembro de 2009).

Análise do material fotográfico obtido

Na pesquisa, efetuada no período de agosto de 2007 a outubro de 2009, foram capturadas 1887 fotografias digitais e 21 vídeos em 18 ocasiões diferentes. Uma análise de todo o material obtido ao longo da pesquisa evidenciou que as fotografias aéreas foram dos tipos quase que vertical, inclinada alta, inclinada baixa e panorâmica. A tomada de um desses diferentes tipos de fotografias dependeu da tarefa, do interesse e da habilidade do operador do sistema. O número de fotografias obtidas em cada missão foi elevado, visto a câmara ser digital e ter sido usado cartão de memória de 4 GB, armazenando centenas de fotografias digitais.

$\mathrm{O}$ uso das fotografias obtidas ocorreu com as seguintes finalidades: individual, multitemporal e para a elaboração de mosaicos não controlados.

\section{Finalidade individual}

Apesar de, em cada sessão fotográfica, terem-se obtido dezenas de fotografias, a finalidade caracterizou-se pelo uso de fotografias individuais selecionadas do tema fotografado.

$\mathrm{Na}$ figura 4 ilustram-se duas fotografias inclinadas individuais, sendo uma inclinada alta e a outra inclinada baixa, de um mesmo talhão florestal.
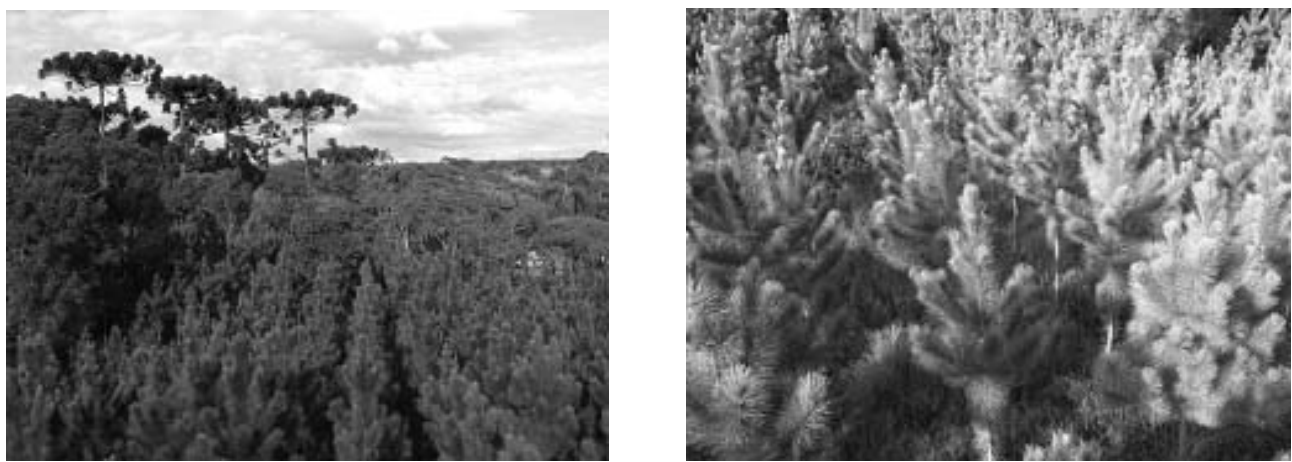

Figura 4. Fotografias inclinada alta (esquerda) e baixa (direita), respectivamente, de um mesmo plantio de Pinus spp. Fonte: Almeida et al., 2009.

Figure 4. High and low oblique photos, respectively, from the same Pinus spp. plantation.
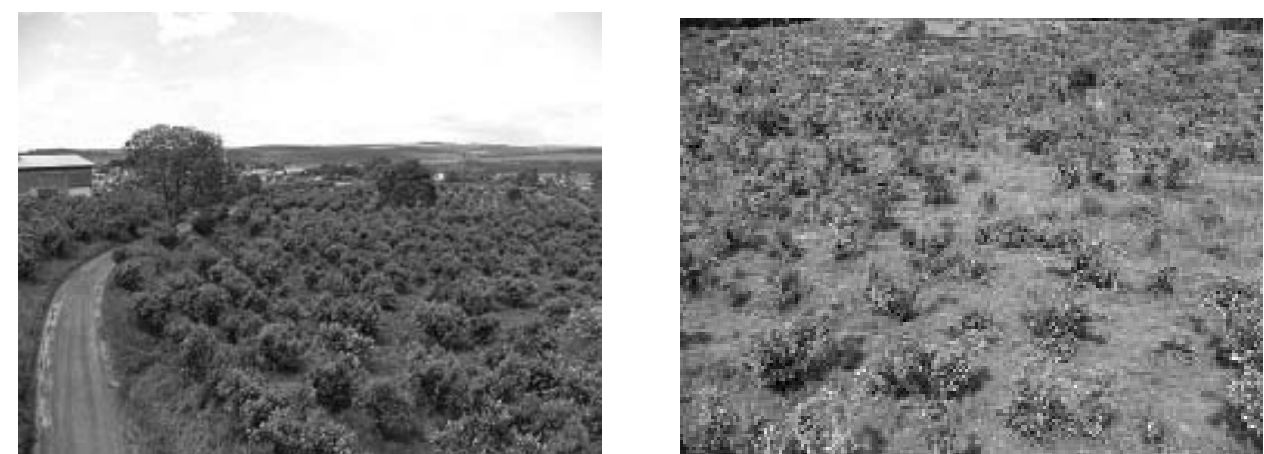

Figura 5. Fotografias inclinadas de um mesmo plantio de Ilex paraguariensis sem poda (esquerda) e com poda recente (direita). Fonte: Disperati, 2009.

Figure 5. Oblique photos of the same Ilex paraguariensis plantation without pruning (left) and with recent pruning (right). Source: Disperati, 2009.

$\mathrm{Na}$ figura 5 ilustram-se fotografias individuais inclinadas em duas situações (sem poda e com poda recente), obtidas a oito metros de altura de um plantio de Ilex paraguariensis com espaçamento 3 x 2 m, localizado no município de Fernandes Pinheiro (PR). 
Nota-se o potencial interpretativo das fotografias individuais mostradas nas figuras 4 e 5 , pois oferecem uma imagem que dificilmente conseguir-se-ia em situações terrestres, devido à altura das árvores em estudo (em média 4,5 m para o Pinus spp. e 2,5 m para Ilex paraguariensis).

\section{Finalidades multitemporais}

Devido a algumas condições contínuas na segunda etapa da pesquisa, como a altura elevada do mastro e a mesma qualidade das fotografias digitais obtidas, foi possível acompanhar a mesma cena em diferentes datas. Esse caso é mostrado na figura 6, representando um quintal localizado em Irati (PR) e evidenciando a eficaz representação visual da cobertura do solo ao longo de três datas. Tal material fotográfico foi obtido como suporte para uma pesquisa em andamento no Departamento de Engenharia Florestal/UNICENTRO, referente ao uso dos quintais na região de Irati. Destaca-se também que foi o único estudo multitemporal efetuado na pesquisa, mas que evidencia novamente a potencialidade desse tipo de fotografias aéreas em face da impossibilidade de se obter tais informações exclusivamente com fotografias terrestres.

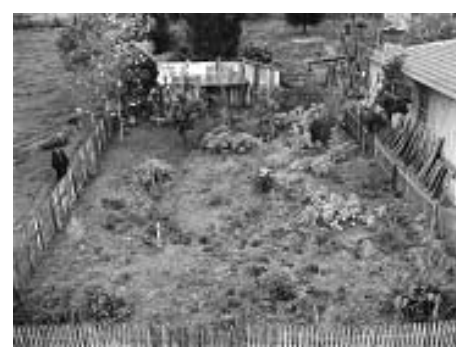

9/9/2008

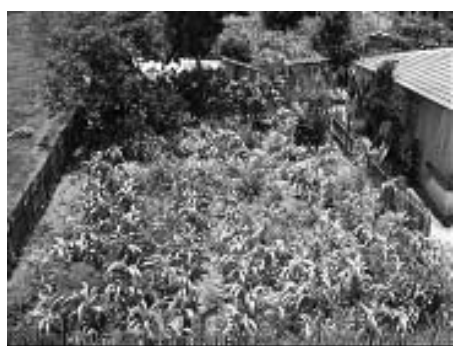

$24 / 11 / 2008$

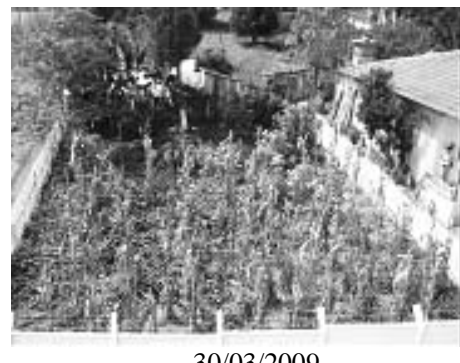

30/03/2009

Figura 6. Fotografias multitemporais (3 datas) de um quintal na região de Irati. Fonte: Almeida et al., 2009.

Figure 6. Multitemporal oblique photography (3 dates) from a yard in the region of Irati.

\section{Finalidade para mosaico}

Os mosaicos, nessa etapa, tiveram origem nas fotografias obtidas lenta e sucessivamente, com o sistema fotográfico proveniente de um giro completo de $360^{\circ}$ ou parcial, controlado a distância por radiocontrole e a oito metros de altura.

Os mosaicos elaborados foram do tipo não controlado e montados artisticamente por meio de software de edição de imagens, o qual possui muitas ferramentas apropriadas para esse tipo de atividade (ex.: ferramenta automate). Antes da montagem do mosaico, as fotografias eram tratadas digitalmente, visando um melhor realce.

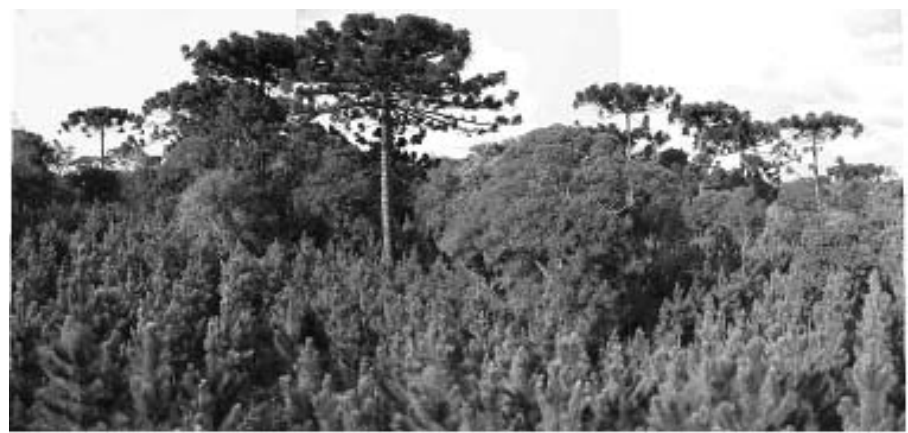

Figura 7. Mosaico não controlado, elaborado com três fotografias. Fonte: Disperati (2008).

Figure 7. Uncontrolled mosaic formed by three photographs. Source: Disperati (2008).

A utilização do número de fotos para compor o mosaico dependeu muito do local e do assunto fotografado, evidenciado nas figuras 7 e 8 .

A figura 7 evidencia um mosaico elaborado com 3 fotografias aéreas de parte de um plantio de Pinus spp., enquanto a figura 8 foi elaborada com 26 fotografias sequenciais. 


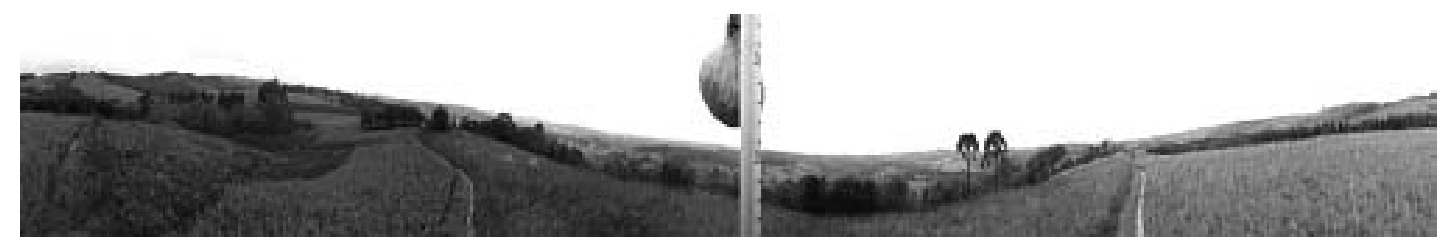

Figura 8. Mosaico do ponto de maior altitude do Campus - ponto de alto risco de incêndio. Fonte: Faria et al. (2009).

Figure 8. Mosaic Uncontrolled mosaic from the point of highest elevation of the campus - point with high fire risk.

Embora não evidenciado nessas figuras e nem na presente pesquisa, uma possível utilização do mastro estendível na pesquisa florestal seria no estudo de árvore individual, podendo ocorrer em plantios comerciais de espécies florestais exóticas ou mesmo em ambiente de floresta natural. Aplicações potenciais desse tipo ocorrem nas áreas de dendrometria/inventário, proteção florestal, manejo, silvicultura e agrossilvicultura.

Aperfeiçoamento do atual sistema e sua situação no contexto de sensoriamento remoto

Apesar das alterações efetuadas na plataforma/sistema fotográfico ao longo do tempo da pesquisa, a experiência apontou alguns itens adicionais que facilitariam a captura fotográfica:

a) facilidade para ligar/desligar a câmara fotográfica por controle remoto;

b) facilidade para acionar o zoom da câmara por controle remoto;

c) estender o mastro a alturas maiores acima do terreno;

d) elevação pneumática das partes estendíveis do mastro.

Desde o erguimento manual do mastro até a altura desejada e a sua descida após a finalização da tomada das fotografias, a câmara estava sempre ligada e necessitando acionar o seu disparo a cada minuto, evitando assim o seu desligamento automático após alguns minutos sem ser acionada. Assim, é de interesse, visando maior conforto operacional do sistema, que haja um comando específico para ligar/desligar a câmara. Tal sistema de acionamento poderá ser idêntico ao utilizado atualmente para disparar a câmara remotamente.

Acessar o comando zoom da câmara é outra facilidade operacional que pode ser implantada no sistema. Na câmara atual em uso, tal facilidade é muito difícil de ser implantada, visto o pequeno tamanho do comando que aciona o zoom. Seria necessário utilizar outra câmara fotográfica, de preferência uma do tipo profissional ou semiprofissional, de maior tamanho e em que seja mais fácil a instalação do acessório para girar o comando zoom, ou, então, que a câmara tenha externamente disponibilidade de tal acesso.

As duas possíveis alterações mencionadas dependem muito do tipo de câmara digital disponível. Algumas marcas e modelos viabilizam o acesso a ambos os comandos, via externa, enquanto outras apenas por via interna, outras por controle remoto e finalmente existem as câmaras que não propiciam tais facilidades.

Elevar o sistema fotográfico instalado na plataforma e no topo do mastro a alturas acima de oito metros é o terceiro fator adicional que facilitaria a captura das fotografias. Elevar manualmente as diversas partes do mastro, assim como propiciar a sua descida de modo seguro e confiável, sempre é uma tarefa que exige muito cuidado e atenção. Qualquer descuido pode fazer com que haja uma queda brusca da plataforma/sistema fotográfico ou mesmo de todo o conjunto mastro/plataforma/sistema fotográfico. Tanto é verdade que, como meio de segurança e precaução, é solicitado aos usuários do mastro a utilização de um capacete. A utilização da elevação pneumática das partes estendíveis por mastro é um quarto aspecto de aperfeiçoamento da captura fotográfica.

A implantação das quatro ou de apenas algumas das sugestões apresentadas tornaria o sistema melhor e mais parecido com os sistemas comerciais disponíveis para a venda.

A experiência prática com o sistema (constituído por um mastro estendível de até $8 \mathrm{~m}$, tripé, plataforma/sistema fotográfico, maleta contendo todo o sistema de captura e observação da imagem 
fotográfica em tempo real e caixa de ferramentas) demonstrou ser necessária uma equipe ideal formada por três pessoas para transporte e utilização adequada. Entretanto, com duas pessoas é possível também a utilização do sistema. Com uma pessoa, a tomada das fotos será feita com muita dificuldade, devido aos aspectos de transporte de materiais e equipamentos, o erguimento/descida das partes estendíveis do mastro e a tomada das fotografias.

$\mathrm{Na}$ ampla gama de sensores remotos disponíveis (fotografias aéreas convencionais e de pequeno formato, imagens de satélite e radar, LIDAR etc.), qual vem a ser o posicionamento da técnica de obtenção de fotografias aéreas por meio de mastro estendível?

A resposta é simples. É uma ferramenta adicional na caixa de ferramentas do sensoriamento remoto. Algumas ferramentas podem ser de uso constante, enquanto outras não. O usuário deverá ter o conhecimento técnico e a sensibilidade de utilizar a técnica do mastro estendível no momento e na situação adequada e, dependendo da situação, poderá ser usado de modo isolado ou complementar com os outros produtos. Em complemento, devido ao baixo custo da técnica do mastro estendível, suas aplicações são limitadas somente pela imaginação dos usuários.

\section{CONSIDERAÇÕES FINAIS}

Por meio da utilização de dois mastros estendíveis e dos aperfeiçoamentos constantes na plataforma e no sistema fotográfico, o projeto de pesquisa apresentou duas etapas em dois anos e meio de execução, desenvolvendo um sistema fotográfico que permite acionar, girar e inclinar uma câmara fotográfica digital e que, instalado no topo de um mastro estendível manualmente, viabiliza a tomada de fotografias aéreas inclinadas, panorâmicas e sequenciais.

A atual plataforma com o sistema fotográfico pode ser ainda aperfeiçoada, visando maior facilidade e conforto na captura fotográfica.

O sistema (mastro estendível, tripé, plataforma e sistema fotográfico e caixa de ferramentas), para ser transportado e utilizado adequadamente no campo, necessita de uma equipe ideal formada por três pessoas.

A análise de todo o material obtido em dezoito ocasiões evidenciou que as fotografias podem ser utilizadas com três finalidades: individual, multitemporal e também na montagem de mosaicos não controlados.

Estudos específicos direcionados à árvore individual realçariam o potencial do mastro estendível para a captura das fotografias aéreas.

\section{AGRADECIMENTOS E NOTA}

À Fundação Araucária, pela concessão de Bolsa de Iniciação Científica para a efetivação do presente projeto.

O presente artigo foi extraído do trabalho científico intitulado "Obtenção de fotografias aéreas digitais por meio de mastro estendível manualmente", submetido, por um dos autores, para a promoção à classe de Professor Associado na UNICENTRO.

\section{REFERÊNCIAS}

ALMEIDA, F. H.; MENDONÇA JÚNIOR, S.; DISPERATI, A. A. Evolução de técnica fotográfica no setor florestal utilizando um mastro estendível manualmente. In: SIEPE - SEMANA DE INTEGRAÇÃO ENSINO, PESQUISA E EXTENSÃO, Guarapuava. Anais... Guarapuava: UNICENTRO, 2009, 4 p.

ALMEIDA, F. H.; DISPERATI, A. A.; MENDONÇA JÚNIOR, S. Utilização de um sistema fotográfico em um mastro estendível visando estudos florestais. In: EAIC, 18., 2009, Guarapuava. Anais... Guarapuava: UNICENTRO, 2009, 4 p.

CLARK MASTS. Fast erecting mast system. Disponível em: <http://www.clarkmasts.com/qtm_masts .php>. Acesso em: 25/05/2008.

COLWELL, R. N. Plataforms for testing multi-sensor equipment. In: SYMPOSIUM ON REMOTE 
SENSING OF ENVIRONMENT, 2., 1962, Ann Arbor. Proceedings... Ann Arbor: The University of Michigan, Institute of Science and Technology, 1963. p. 7 - 49.

DISPERATI, A. A. Obtenção e uso de fotografias aéreas de pequeno formato. Curitiba: FUPEF/UFPR, 1991. 290 p.

DISPERATI, A. A. Obtenção de fotografias aéreas digitais por meio de um mastro estendível manualmente. Irati: Unicentro, 2009. 37 p.

DISPERATI, A. A.; FOFANO JÚNIOR, A. F.; MORGADO, M. Fotografias inclinadas $35 \mathrm{~mm}$ multitemporais, colorido normal e infravermelho colorido, da Praça Santos Andrade, Curitiba. Floresta, Curitiba, v. 23, n. 12, p. 15 - 33, 1993.

DISPERATI, A. A.; OLIVEIRA FILHO, P. C.; BERNARDI, D. Aplicações na floresta com reflorestamentos. In: DISPERATI, A. A.; AMARAL, R. F.; SCHULER, C. A. B. Fotografias aéreas de pequeno formato: aplicações ambientais. Guarapuava: Unicentro, 2007. p. 95 - 128.

DISPERATI, A, A.; ALMEIDA, F. H.; MENDONÇA JÚNIOR, S.; PEINHOPF, C.; DALGALlO, B. Uso do mastro para a captura de fotografias para estudos florestais. IN: SEMINÁRIO DE ATUALIZAÇÃO EM SENSORIAMENTO REMOTO E SISTEMAS DE INFORMAÇÕES GEOGRÁFICAS APLICADOS À ENGENHARIA FLORESTAL, 8., 2008, Curitiba. Anais... Curitiba: FUPEF, 2008. p. 108 - 115.

FARIA, A. B. C.; OLIVEIRA FILHO, P. C.; DISPERATI, A. A.; ALMEIDA, F. H.; SAUERBIER, W. Confirmação em campo das informações levantadas no plano de prevenção de incêndios florestais do Campus da UNICENTRO/Irati. In: SEMANA DE ESTUDOS FLORESTAIS E SEMINÁRIO DE ATUALIZAÇÃO FLORESTAL. 10., 2008, Irati. Anais... Irati: UNICENTRO, 2009, 3 p.

FLOATOGRAPH. Floatograph FM series masts. Disponível em: <http://www.floatograph.com/fmseries /intro.htm>. Acesso em: 25/05/2008.

FLOATOGRAPH (a). Telescopic mast photography system. Disponível em: <http://www.giraffecam.com>. Acesso em: 25/05/2008.

WENZLAU ENGINEERING. Telescoping masts. Disponível em: <http://www.wenzlau.com/masts.htm>. Acesso em: 25/05/2008. 